\title{
Strengthening of RC Framed Structure Using Energy Dissipation Devices
}

\author{
Dr. R. B. khadiranaikar ${ }^{*}$, Dr. B. G. Naresh kumar ${ }^{*}$, Md. Aqeeb hussain ${ }^{* *}$, \\ Avinash Gornale
}

\begin{abstract}
A large numbers of existing buildings in India are severely deficient against earthquake forces and the number of such buildings is growing very rapidly. This paper presents a way of using energy dissipation devices for seismic strengthening of a $R C$ framed structure. The objective was to improve the seismic performance of the building to resist the earthquake. The viscous dampers are used as an energy dissipation device in the form of single, double, inverted $V$, $V$ type of dampers with different percentages of damping such as $10 \%, 20 \%$ and $30 \%$ to prevent building from collapse in a major earthquake and also to control the damage during earthquake. The performance of the buildings is assessed as per the procedure prescribed in ATC-40 and FEMA 356.
\end{abstract}

Keywords: seismic performance, energy dissipation devices, non-linear static analysis.

\section{Introduction}

Earthquake is one of the major natural hazards to the life on the earth and has affected countless cities and villages of almost every continent. The damage caused by earthquakes are mostly to man mad structures. Hundreds of small earthquakes occur around the world every day and every year earthquakes take the lives of thousands of people. Therefore, it is necessary to design structures that are earthquake resistant. Earthquake engineering has gained lots of attention in recent years since it ensures design of safe structures, which can safely withstand earthquakes of reasonable magnitude. Conventional seismic design attempts to make building that do not collapse under strong earthquake shaking, but may sustain damage to non-structural elements and to some structural members in the building. This may cause the building to be non-functional after the earthquake, which may be problematic in some structures, like Hospitals, which need to remain functional after an earthquake. Special techniques are required to design buildings such that they remain practically undamaged even in a severe earthquake. The energy dissipation devices are recognized as a suitable technique to control the seismic response of the structure and reduce the damage caused by earthquake. EDD can absorb a portion of earthquake-induced energy in the structure and minimize the energy dissipation demand on the primary structure members such as beams, column and walls. These devices can substantially reduce the inter-story drift and, consequently, non-structural damage. These devices can improve the performance of the building to resist the earthquake.

\subsection{Objectives of the study}

The main objectives of this study can be listed as follows;

- To estimates the performance point and collapse load for the considered building for study under seismic loading.

- To study the behavior of the building for incremental lateral load.

- To estimate the increased performance of the building by using viscous dampers as a retrofitting method.

\section{Illustrative Examples}

The Layout of plan having $5 \mathrm{X} 4$ bays of equal length of $5 \mathrm{~m}$ Figure 1 . The buildings considered are Reinforced concrete frame building of ten storey's with regular configurations. The storey height is kept uniform of $3 \mathrm{~m}$ for building model which is as fallows, 


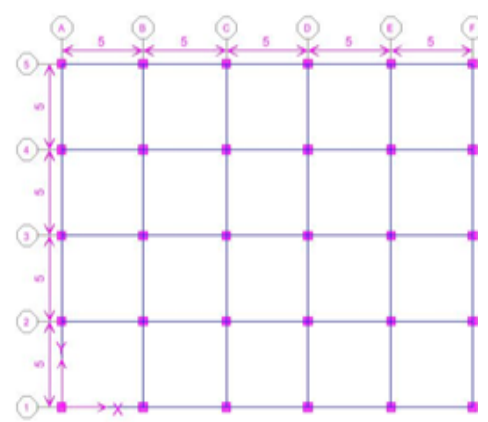

Figure 1.plan of the building

\section{Analysis Methods}

Analysis methods are broadly classified as linear static, linear dynamic, nonlinear static and nonlinear dynamic methods. In these the first two methods are suitable when the structural loads are small and no point, the load will reach to collapse load and are differs in obtaining the level of forces and their distribution along the height of the structure. Whereas the non- linear static and non-linear dynamic analysis are the improved methods over linear approach. During earthquake loads the structural loading will reach to collapse load and the material stresses will be above yield stresses. So in that case material nonlinearity and geometrical nonlinearity should be incorporated into the analysis to get better results. These methods also provide information on the strength, deformation and ductility of the structures as well as distribution of demands.

\subsection{Equivalent Static Method}

Equivalent static method of analysis is a linear static procedure, in which the response of building is assumed as linearly elastic manner. The analysis is carried out as per IS1893-2002 (Part 1)

\subsection{Response Spectrum Method}

Linear dynamic analysis of the building models is performed using ETABS. The lateral loads generated by ETABS correspond to the seismic zone III and 5\% damped response spectrum given in IS 1893-2002 (Part 1). The fundamental natural period values are calculated by ETABS, by solving the Eigen value problem of the model. Thus, the total earthquake load generated and its distribution along the height corresponds to the mass and stiffness distribution as modelled by ETABS.

\subsection{Pushover Analysis}

Pushover analysis is one of the methods available to understand the behavior of structures subjected to earthquake forces. As the name implies, it is the process of pushing horizontally with a prescribed loading pattern incrementally until the structure reaches a limit state [ATC-40 1996]. The non linear static analysis (pushover analysis) is promising tool for seismic performance of existing and new structure. Pushover analysis gives an estimate of seismic capacity of the structural system and its components based on its material characteristics and detailing of member dimensions.

The pushover analysis is essentially a step-by-step analysis procedure that applies a distribution of lateral story forces to a structural model develop from the moment curvature properties of the members the technique can be useful in evaluation structural response behavior and potential collapse mechanism.

The pushover or capacity curve represents the lateral displacements as the function of force applied to the structure. Location of hinges in various stages can be obtained from pushover curve as shown in Figure2.The range $\mathrm{AB}$ is elastic range, $\mathrm{B}$ to $\mathrm{IO}$ is the range of immediate occupancy, IO to LS is the range of life safety, and LS to CP is the range of collapse prevention [ATC-40]. If all the hinges are within the CP limit then the structure is said to be safe. However, depending upon the importance of structure the hinges after IO range may also need to be retrofitted.

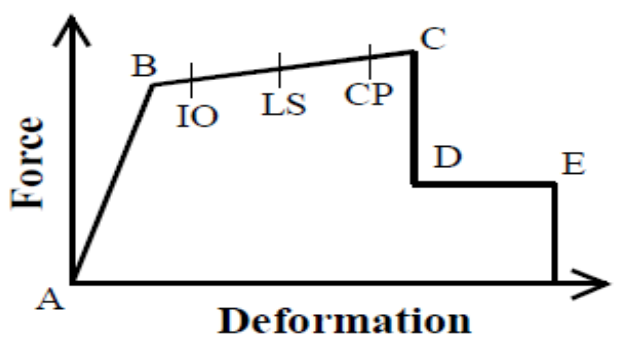

Figure 2.Different Stages of Plastic Hinge Formation. 


\subsection{Performance Point}

The maximum structural displacement expected for the demand earthquake ground motion represents the performance point. Performance point can also be defined as a condition for which the seismic capacity of the structure is equal to the seismic demand imposed on the structure by the specific ground motion. It can be obtained by the intersection of capacity spectrum and demand spectrum. To get the capacity spectrum it is necessary to convert the capacity curve, which is in terms of base shear and roof displacement, to what is called as capacity spectrum, which is a representation of capacity curve in Acceleration-Displacement Response Spectra (ADRS) format. The demand spectrum is the design acceleration spectrum given in IS: 1893 (Part 1)2002 modified for $5 \%$ damping (for the concrete structures), based on desired response reduction factor (depending on type of lateral load resisting system) and foundation soil type.

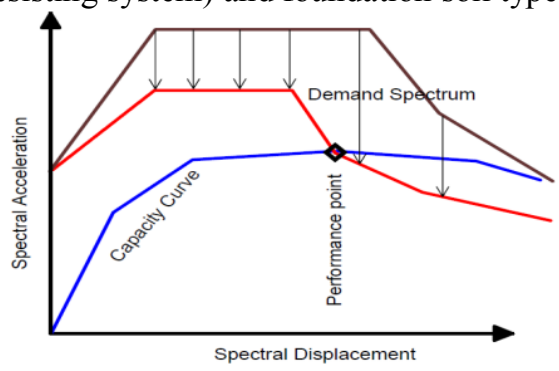

Figure 3.Performance Point.

\subsection{Energy absorption with different dampers}

\section{Results And Discussion}

The energy dissipation devices can absorb portion of energy induced during earthquake. The dampers used are single diagonal, double diagonal, inverted $\mathrm{V}$ and $\mathrm{V}$ type of viscous damper at different percentage of damping such viz $10 \%, 20 \%$ and $30 \%$. The viscous dampers reduce the base shear in the building both in $\mathrm{X}$ and $\mathrm{Y}$ direction as the percentage of damping increases. By reducing base shear in the building the earthquake can be resisted.
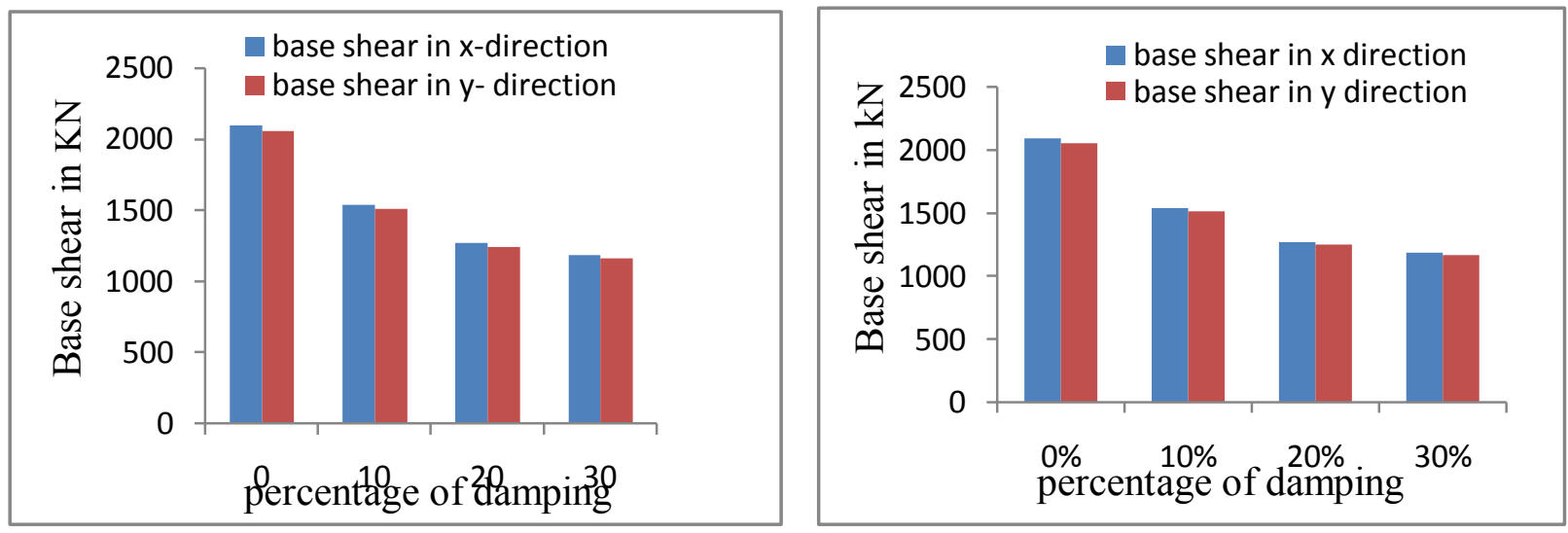

Figure 4. The variation of base shears with different percentage of damping in single diagonal damper.

Figure 5.The variation of base shears at different percentage of damping with double diagonal dampers.

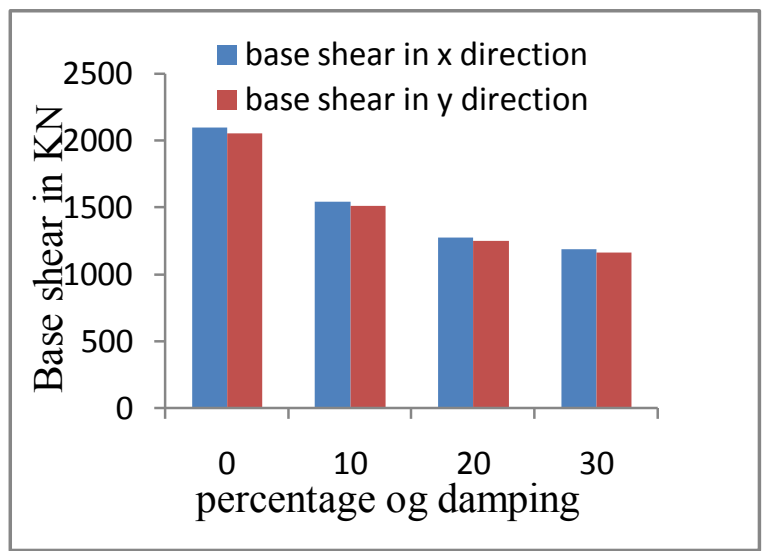

Figure 6.The variation of base shears at different percentage of damping with inverted $\mathrm{V}$ type dampers. 


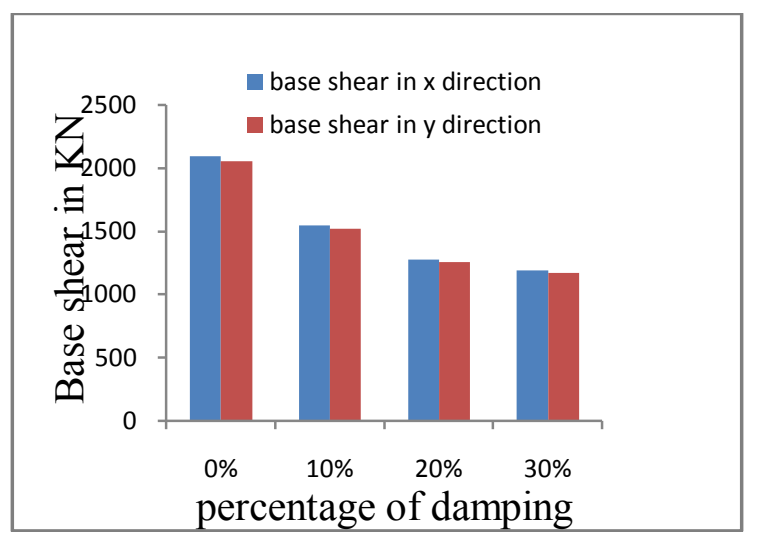

Figure 7.The variation of base shears at different percentage of damping with $V$ type dampers.

In the Figure 4 the base shear of the structure can be reduced with the use of energy dissipation devices as viscous dampers. By the comparison of this Figure one can find out that the variation of base shear with different percentage of damping. This is because energy dissipation devices absorb energy during earthquake. So the variation of base shear with $0 \%, 10 \%, 20 \%$ and $30 \%$ of damping is $2093.23 \mathrm{kN}, 1536.28 \mathrm{kN}, 1268.08 \mathrm{kN}$ and $1183.08 \mathrm{kN}$.

Figure 5 shows the variation of base shear and percentage of damping. At different percentage of damping there is a reduction in base shear both in $\mathrm{X}$ and $\mathrm{Y}$ direction the reduction in base shear increase the capacity of the building to resist the earthquake. There is no much difference between reduction of base shear in single and double diagonal type of viscous dampers.

From Figure 6 the result shows that there is a significant reduction in base shear at different percentage of damping. The comparison shows that the reduction of base shear in inverted $\mathrm{V}$ type of dampers is less compare to single and double diagonal dampers.

Figure 7 show the reduction of base shear after installing $\mathrm{V}$ type of dampers at different percentage of damping. So by reducing base shear in the building the performance of the building can be increased during earthquake. The reduction in base shear of inverted $\mathrm{V}$ and $\mathrm{V}$ type dampers is almost same.

\subsection{Hinge status along $x$-direction with different dampers.}

Performance point determined from pushover analysis is the point at which the capacity of the structure is exactly equal to the demand made on the structure by the seismic load. The performance of the structure is assessed by the state of the structure at performance point. This can be done by studying the status of the plastic hinges formed at different locations in the structure when the structure reaches its performance point. It is therefore important to study the state of hinges in the structure at performance point. The status of hinges at performance point for different models considered for the analysis i.e. for all models with different percentage of damping.

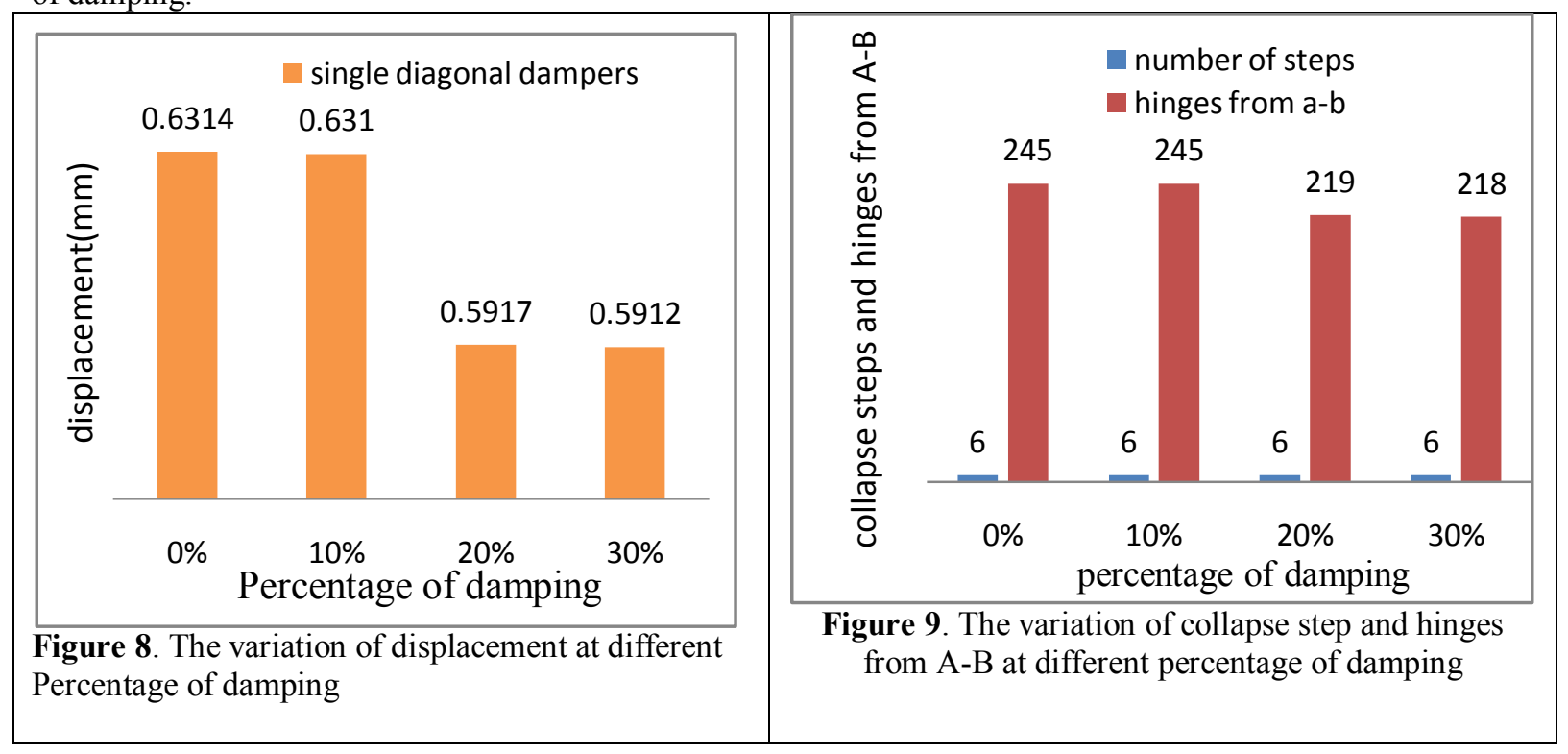




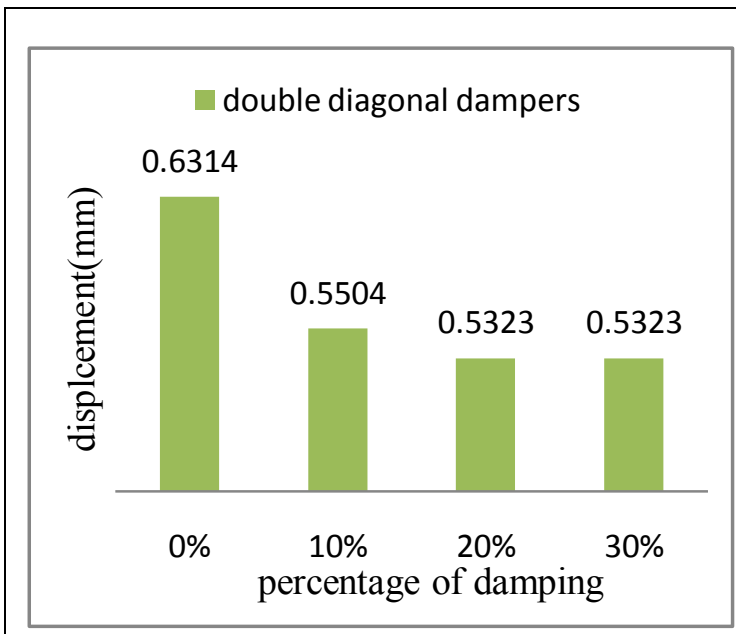

Figure 10. the variation of displacement at different percentage of damping

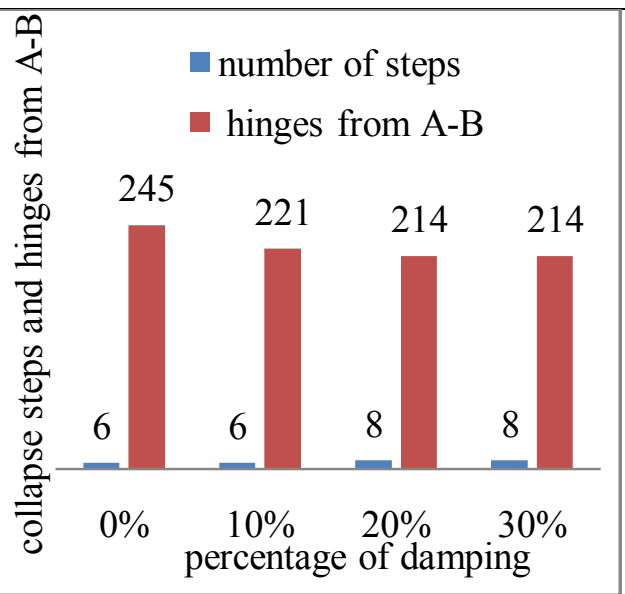

Figure 11. the variation of collapse step and hinges from A-B at different percentage of damping

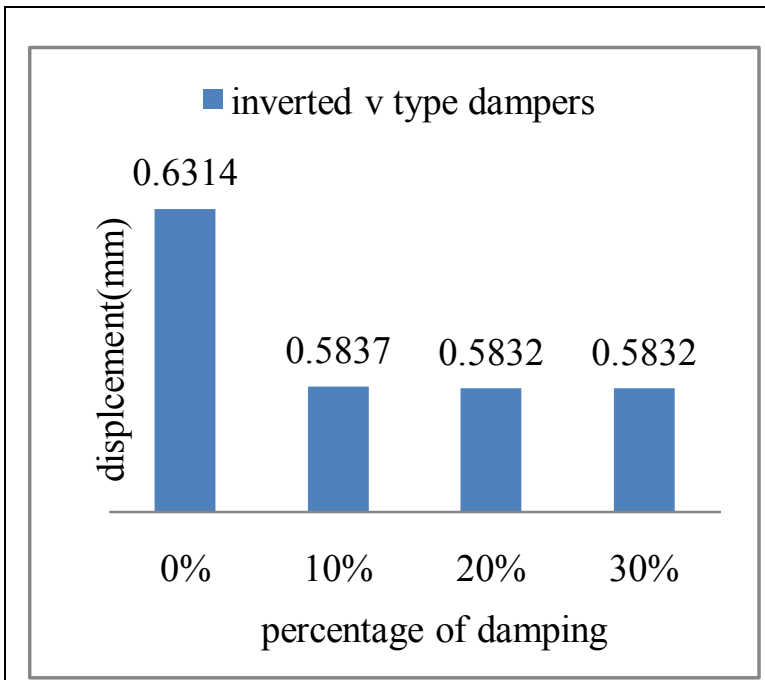

Figure 12. the variation of displacement at different percentage of damping

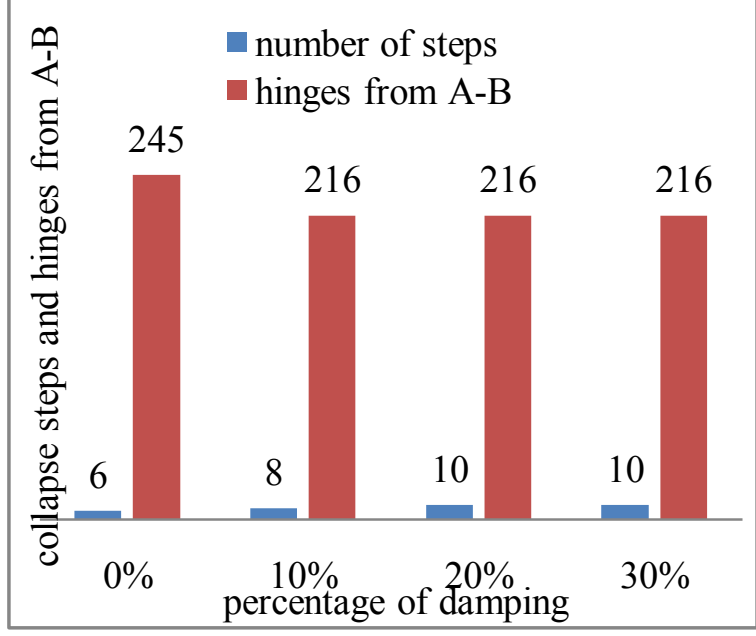

Figure 13. the variation of collapse step and hinges from A-B at different percentage of damping

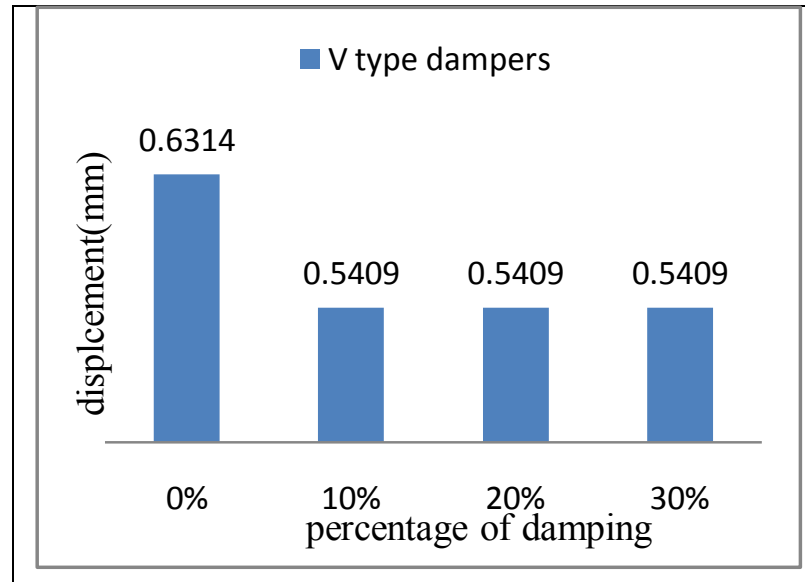

Figure 14. the variation of displacement at different percentage of damping

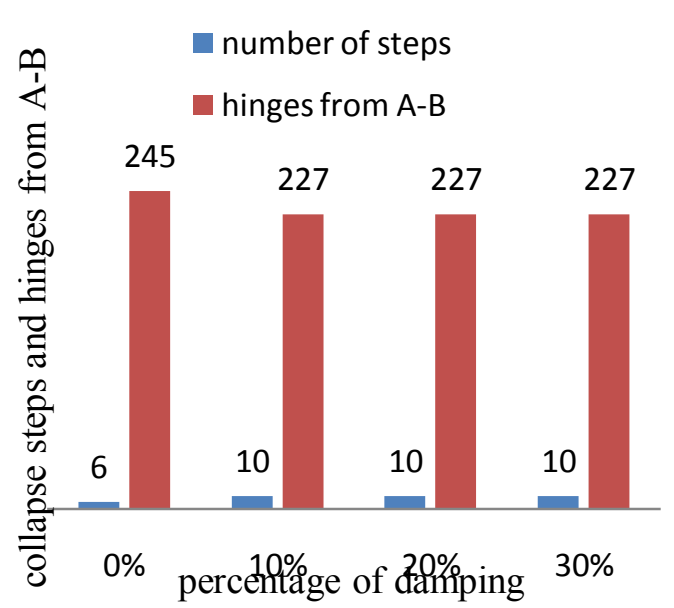

Figure 15. the value of collapse step and hinges from A-B at different percentage of damping 
Figure 8 show that the displacement without dampers is $0.6314 \mathrm{~mm}$. After installation of energy dissipation devices the displacement at $10 \%$ of damping reduces to $0.6310 \mathrm{~mm}$, at $20 \%$ of damping it reduces to $0.5917 \mathrm{~mm}$ and at $30 \%$ of damping it reduces to $0.5912 \mathrm{~mm}$.

In the Figure 9 after installation of dampers with different percentage of damping the number of Hinges in the region A-B is reduced and different percentage of damping building collapse at step 6 .

Figure 10 show the variation of displacement with different percentage of damping. At different percentage of damping there is a significant reduction in displacement. Reduction in displacement increases the capacity of the building to resist the earthquake. When we use double diagonal type of viscous dampers the displacement is more compare to single diagonal dampers.

In the Figure 11 the result show that the number of hinges in the region A-B is reduce at different percentage of damping. The building collapse at step 6 with $0 \%$ and $10 \%$ of damping, at step 8 with $20 \%$ and $30 \%$ of damping.

From Figure 12 the result shows that there is a reduction at different percentage of damping. By comparing the displacement of inverted $\mathrm{V}$, single diagonal and double diagonal type of dampers. The displacement in double diagonal dampers is more.

Figure 13 show the variation of collapse step and hinges in the region A-B. After installation of dampers at $10 \%$ of damping building collapse at step 8 then at $20 \%$ and $30 \%$ f damping building collapse at step10. The number of hinges forming in the region is 216 at different percentage of damping.

In the Figure 14 the displacement in the building without damper is $0.6314 \mathrm{~mm}$. After installation of dampers the displacement in the building is constant i.e. $0.5409 \mathrm{~mm}$ at different percentage of damping.

Figure 15 shows that building without dampers collapse at step6. After installing dampers with different percentage of damping the building collapse at constant step i.e. step 10. The number of hinges forming in the region without dampers is 245 . After installation of dampers in the building the hinges in the region forming are constant i.e. 227. By reducing hinges in the building earthquake can be resisted.

\section{3 fundamental natural periods with different types of viscous dampers}

As per IS: 1893 (part 1) 2002 the fundamental natural period of vibration of a building is given by empirical formulae, which depend on the height of the building, and base dimensions of the structure. It also states that a free vibration analysis may be performed as per established methods to obtain the natural periods of the structure. It has been observed in all types of viscous dampers that the value of fundamental natural period is increasing as the percentage of damping increases.

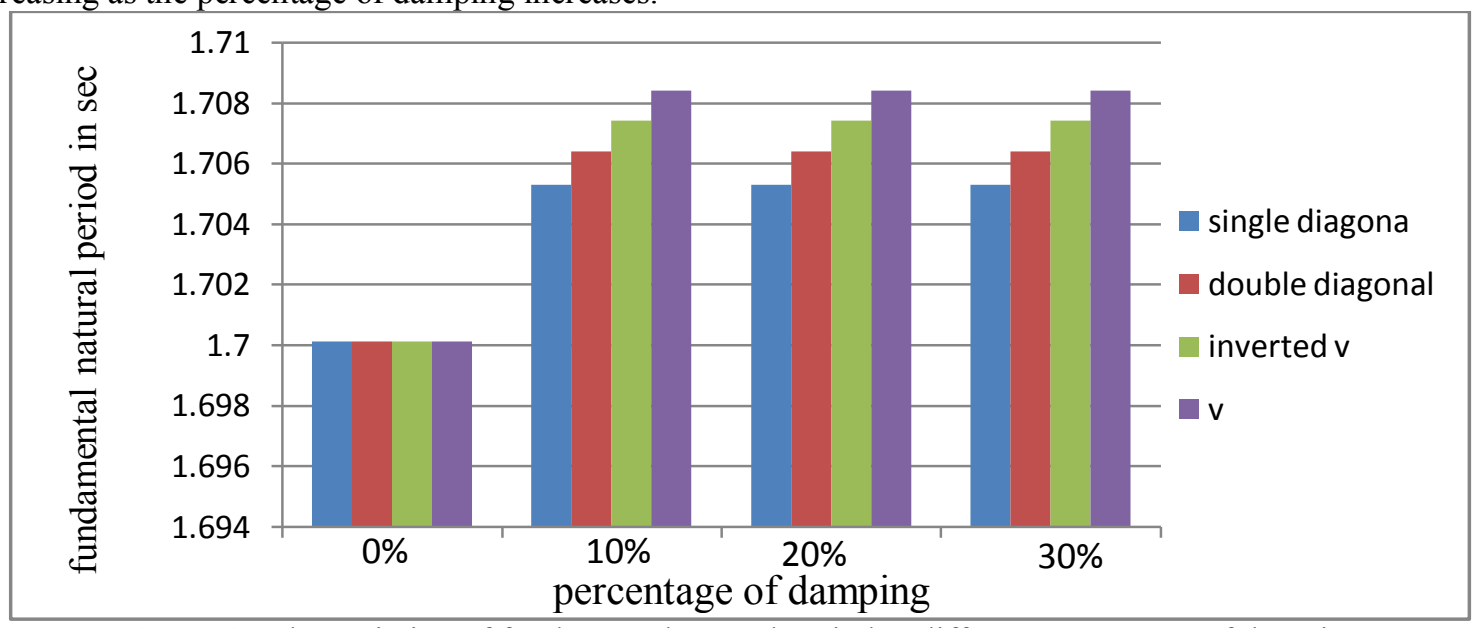

Figure 16. The variation of fundamental natural period at different percentage of damping

from Figure 16 result show that at $0 \%$ of damping the fundamental natural period is $1.7001(\mathrm{sec})$. Then after installing single diagonal type of dampers at $10 \%, 20 \%$ and $30 \%$ of damping the fundamental natural period is increases to $0.30 \%$ by which building becomes more flexible during earthquake.

In double diagonal type of dampers the fundamental natural period at $10 \%, 20 \%, 30 \%$ of damping the fundamental natural period increases to $0.37 \%$ by which building becomes more flexible during earthquake.

In inverted $\mathrm{V}$ type of dampers the fundamental natural period at different percentage of damping increases to $0.43 \%$ by comparing with single diagonal type of bracing the fundamental natural period of inverted $\mathrm{v}$ type of dampers make the building more flexible.

For V type of dampers the fundamental natural period at different percentage of damping increases to $0.48 \%$ which increases the flexibility of the building. 


\subsection{Performance level in $\mathrm{X}$ and $\mathrm{Y}$ direction}

The performance level describes a limiting damage condition which may be considered satisfactory for a given building and a given ground motion. The limiting condition is described by the physical damage within the building, the threat to life safety of the buildings occupants created by the damage, and post-earthquake serviceability of the building. Target performance levels for structural and non structural systems are specified independently. Structural performance levels are given names and number of designation. While nonstructural performance levels are given names and letter designation. Building performance levels are a combination of a structural performance level and nonstructural performance level.

Table 4.10 the values for comparison of results in $\mathrm{x}$ direction with different dampers

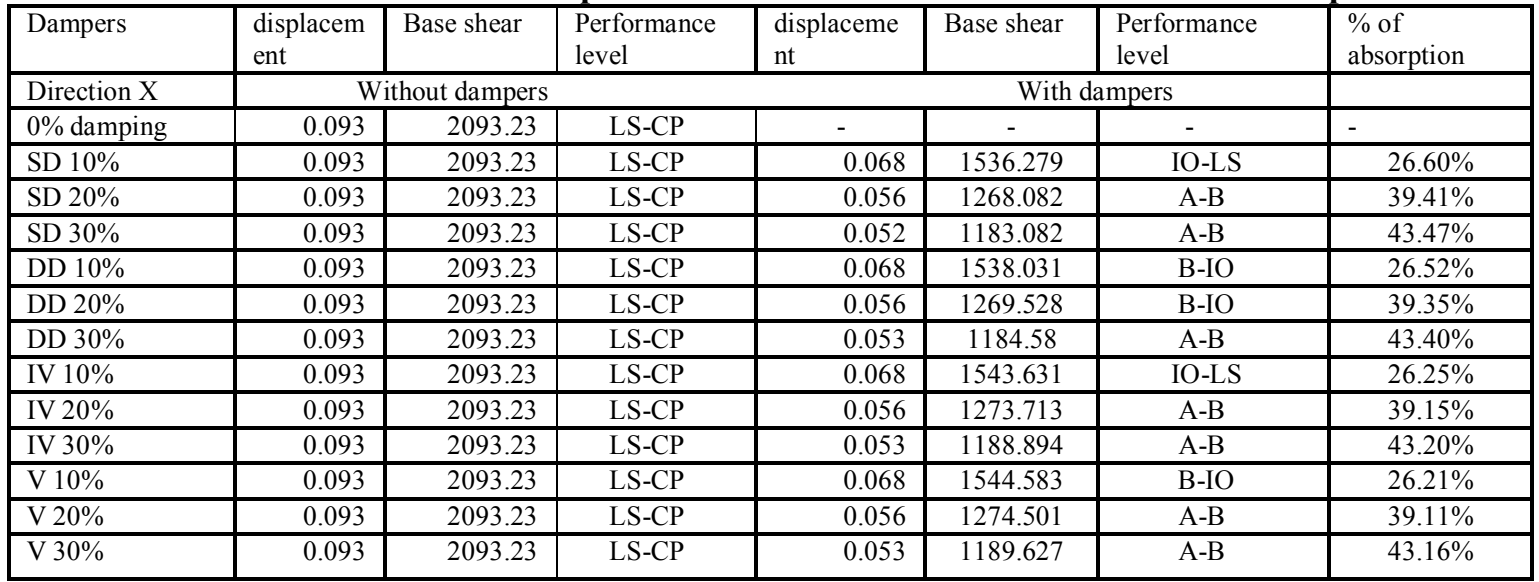

From the table 4.10 it is clear that in $\mathrm{x}$-direction for model without damper the performance level is in between life safety level to collapse prevention level (LS-CP). So loss is acceptable in this region, then after installing damper at $10 \%$ of damping the performance level comes between immediate occupancy level to life safety level (IO-LS) so after installing dampers it comes to minor repair for single diagonal and inverted $\mathrm{V}$, then at $20 \%$ and $30 \%$ it comes to elastic region i.e. (A-B) i.e. no damage region. For double diagonal and $\mathrm{V}$ type of viscous dampers at $10 \%$ of damping the performance level is in between B-IO so it is in damage control range then at $20 \%$ and $30 \%$ of damping it comes to A-B region i.e. no damage region.

Table 4.11 the values for comparison of results in $\mathrm{Y}$ direction with different dampers

\begin{tabular}{|c|c|c|c|c|c|c|}
\hline dampers & displacement & Base shear & $\begin{array}{c}\text { Performance } \\
\text { level }\end{array}$ & Base shear & $\begin{array}{c}\text { Performance of } \\
\text { level }\end{array}$ & $\begin{array}{c}\text { With dampers } \\
\text { absorption }\end{array}$ \\
\hline Direction Y & \multicolumn{3}{|c|}{ Without dampers } & - & - \\
\hline $0 \%$ & 0.095 & 2053.349 & LS-CP & IO-LS & $26.63 \%$ \\
\hline SD 10\% & 0.095 & 2053.349 & LS-CP & 1506.968 & A-B & $39.41 \%$ \\
\hline SD 20\% & 0.095 & 2053.349 & LS-CP & 1243.888 & $43.47 \%$ \\
\hline SD 30\% & 0.095 & 2053.349 & LS-CP & 1160.656 & A-B & IO-LS \\
\hline DD 10\% & 0.095 & 2053.349 & LS-CP & 1508.689 & $24.82 \%$ \\
\hline DD 20\% & 0.095 & 2053.349 & LS-CP & 1245.309 & A-B & $38.06 \%$ \\
\hline DD 30\% & 0.095 & 2053.349 & LS-CP & 1161.982 & A-B & $42.10 \%$ \\
\hline IV 10\% & 0.095 & 2053.349 & LS-CP & 1514.13 & B-IO & $26.26 \%$ \\
\hline IV 20\% & 0.095 & 2053.349 & LS-CP & 1249.379 & A-B & $39.15 \%$ \\
\hline IV 30\% & 0.095 & 2053.349 & LS-CP & 1166.172 & A-B & $43.20 \%$ \\
\hline V 10\% & 0.095 & 2053.349 & LS-CP & 1515.072 & B-IO & $26.21 \%$ \\
\hline V 20\% & 0.095 & 2053.349 & LS-CP & 1250.157 & A-B & $39.11 \%$ \\
\hline V 30\% & 0.095 & 2053.349 & LS-CP & 1166.897 & A-B & $43.18 \%$ \\
\hline
\end{tabular}

SD-single diagonal, DD-double diagonal, IV-inverted $\mathrm{V}$ and $\mathbf{V}$ type of dampers

From table 4.11 it is clear that in y-direction for model without damper the performance level is in between life safety level to collapse prevention level (LS-CP). So loss is acceptable in this region then after installing damper at $10 \%$ of damping the performance level comes between immediate occupancy level to life safety level (IO-LS) so after installing dampers it comes to minor repair for single diagonal and double diagonal then at $20 \%$ and $30 \%$ it comes to elastic region i.e. (A-B) i.e. no damage region. For inverted $\mathrm{V}$ and $\mathrm{V}$ type of viscous dampers at $10 \%$ of damping the performance level is in between B-IO so it is in damage control range then at $20 \%$ and $30 \%$ of damping it comes to A-B region i.e. no damage region. 


\section{Conclusions:}

The aim of the project is to improve the capacity of the building to resist the earthquake using energy dissipation devices, particularly viscous dampers of different types such as single diagonal, double diagonal, inverted $\mathrm{V}$ and $\mathrm{V}$ type of viscous dampers.

- The comparison of the results both in $\mathrm{X}$ and $\mathrm{Y}$ direction of all the type of viscous dampers indicates that by installing dampers in the structures we can reduce the base shear of the building. So by reducing base shear in the concrete frame structure, we can increase the capacity of the building to resist the earthquake.

- By comparing the results of both single diagonal and double diagonal type of viscous dampers the percentage reduction in base shear of single diagonal is $26.60 \%$ and double diagonal is $26.52 \%$. So the percentage reduction in double diagonal is low but providing double diagonal type of viscous dampers is better than single diagonal type of viscous dampers, because we don't know in which direction earthquake will occur.

- By installing the viscous dampers of different types at $10,20,30 \%$ of damping we can increase the fundamental natural period which makes the structure more flexible during earthquake. And by comparing fundamental natural period of all the four type of viscous dampers the increase in fundamental natural period of $\mathrm{V}$ type of viscous damper is more.

- By comparing the results of performance point in $\mathrm{x}$ and $\mathrm{y}$ direction, we can conclude that after installing dampers the performance level from region LS-CP comes to region A-B. So, by installing dampers we can improve the performance level of the building to resist the earthquake.

- By installing viscous dampers we can reduce the displacement in the building which makes the building earthquake resistant.

- Model without dampers collapse at step 6, after installing single diagonal type of dampers building also collapse at step 6, in double diagonal type of dampers building collapse at step 8 and for both inverted V and $\mathrm{V}$ type of dampers building collapse at step 10.so by installing dampers with different percentage of damping in the structure we can increase the lateral load coming to the building during earthquake.

\section{References:}

[1]. Vijay Chachapara, Sharadkumar Purohit and P. V. Patel. (2011). "Seismic Response Control of the Building using Passive Devices" Civil Engineering Department, Institute of Technology, Nirma University, Ahmedabad 382481

[2]. ali sehat tabatabaei. (2003). "Energy Dissipation Systems for Siesmic Resistance" civil engineering university of east London.

[3]. Fahim sadek, Bijan mohraz And Michael a riley. (2000). "Improved Linear Procedures for Analysis of Structures with Passive Energy Dissipation Devices" National Institute of Standards and Technology, Gaithersburg, MD

[4]. K. Sathish Kumar, C. Antony Jeyasehar and K. Muthumani. (2012). "A Design Methodology for Supplemental damping for Seismic Performance Enhancement of Frame Structures" asian journal of civil engineering (building and housing) vol. 13, no. 5 (2012) pages 659-678

[5]. IS: 1893 - 2002 (Part 1), "Criteria for Earthquake Resistant Design of Structures", part 1-General provisions and buildings, fifth revision, Bureau of Indian Standard, New Delhi, India.

[6]. IS: 456-2000., "Code of Practice for Plain and Reinforced Concrete", Bureau of Indian Standard, New Delhi, India

[7]. ATC, 1996, "Seismic Evaluation and Retrofit of Concrete Buildings", Volume 1,

[8]. ATC-40 Report, Applied Technology Council, Redwood City, California.

[9]. Federal Emergency Federal Agency, FEMA-356. Pre-standard and Commentary

[10]. for Seismic Rehabilitation of Buildings. Washington DC, 2000.

[11]. Durgesh C. Rai. "Supplemental Damping for Seismic Strengthening: a Case Study". Department of Earthquake Engineering, University of Roorkee, Roorkee 247 667, India.

[12]. S.K. Ahirwar, S.K. Jain and M. M. Pande. (2008). "Earthquake Loads on Multistory Buildings as per IS: $1893-1984$ and IS: 18932002: A Comparative Study” The 14 World Conference on Earthquake Engineering October 12-17, 2008, Beijing, China. 